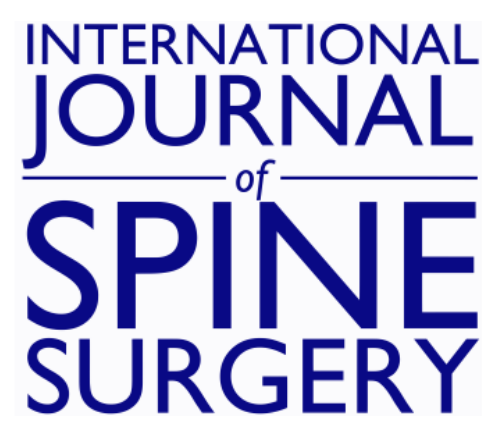

\title{
Transforaminal Lumbar Interbody Fusion With Viable Allograft: 75 Consecutive Cases at 12-Month Follow-up
}

\author{
WILLIAM C. TALLY, H. THOMAS TEMPLE, TY SUBHAWONG and TIMOTHY GANEY
}

Int J Spine Surg 2018, 12 (1) 76-84

doi: https://doi.org/10.14444/5013

http://ijssurgery.com/content/12/1/76

This information is current as of April 25, 2023.

Email Alerts Receive free email-alerts when new articles cite this article. Sign up at:

http://ijssurgery.com/alerts

The International Journal of Spine Surgery

2397 Waterbury Circle, Suite 1,

Aurora, IL 60504, Phone: +1-630-375-1432 


\title{
Transforaminal Lumbar Interbody Fusion With Viable Allograft: 75 Consecutive Cases at 12-Month Follow-up
}

\author{
WILLIAM C. TALLY, ${ }^{1}$ H. THOMAS TEMPLE,${ }^{2}$ TY SUBHAWONG,${ }^{3}$ TIMOTHY GANEY $^{4}$ \\ ${ }^{I}$ GA Regents University/Medical College of Georgia, Athens Campus; Athens Orthopedic Clinic, Athens, Georgia, ${ }^{2}$ Nova Southeastern, Fort Lauderdale, Florida, \\ ${ }^{3}$ University of Miami, Florida, ${ }^{4}$ Atlanta Medical Center, Atlanta, Georgia
}

\begin{abstract}
Background: When conservative treatments fail to alleviate the discomfort of abnormal motion, spinal fusion has been shown to provide symptomatic treatment for spinal instability, stenosis, spondylolisthesis, and symptomatic degenerative disc disease. The trend and rates of fusion over the past few years have been dramatic in the United States. Accompanying that higher incidence has been the shifting from traditional open surgery to minimally invasive techniques to reduce scar tissue formation, extent of muscle stripping, and muscle retraction which all have been shown to adversely affect outcomes. Other reasons supporting the widespread transition to minimally invasive surgical (MIS) techniques include decreased postoperative pain, decreased intraoperative blood loss, shorter postoperative hospital stay, faster return to normal activity, and reduced reoperation rates. Spinal fusion procedures rely on a bony fusion substrate in addition to fixation hardware. While available grafting options include autogenous, allogeneic, and synthetic materials, recent interest in viable allograft material with living cells has drawn attention and attraction for incorporating a biologic basis for regenerative consideration. A recent viable allograft, complete with cellular and designated bone carrier (VIA Graft, Vivex Biomedical, Marietta, Georgia) has been developed. This study represents a retrospective review of a single-practice, single-surgeon evaluation of the product in 75 consecutive patients for fusion by computed tomography (CT) and radiographic evaluation at 12 months in conjunction with a MIS approach. Viable allograft was used to fill the peri-implant space, and central implant lumen was filled with a cancellous bone sponge soaked in perivertebral bone marrow. Posterolateral supplementation was attained with beta-tricalcium phosphate as a bulking agent.
\end{abstract}

Methods: A retrospective review identified patients treated for both primary and revision surgery who received VIA Graft cellular bone matrix material in minimally invasive interbody fusion (MIS-TLIF) with a minimum of 12month follow up. The patient diagnoses included radiculopathy in all instances and varied collateral indications such as foraminal collapse, recurrent disc herniation, and spondylolisthesis to which pain and morbidity had been unresolved by conservative treatment. Adverse events including infection, revisions, and evidence of immune response were evaluated and patient comorbidities defined for the entire population of patients. Patient fusion status was assessed using thin slice CT by 2 independent radiologists separate from the surgeon. There were 75 consecutive adult patients with degenerative conditions of the lumbar spine who underwent MIS-TLIF surgery of which $40(53 \%)$ were male and $35(47 \%)$ were female. Mean age, height, and weight were 58 years, $170.18 \mathrm{~cm}(67 \mathrm{in})$, and $88.45 \mathrm{~kg}(195 \mathrm{lbs})$, respectively. The mean body mass index was 30 . There were 16 patients $(21 \%)$ who smoked and $12(16 \%)$ with a history of diabetes. Independent blinded review of fusion was obtained by a board certified musculoskeletal radiologist and an experienced board certified orthopaedic surgeon to assess patient fusion status. Spinal segments were deemed fused if 12-month CT scans demonstrated evidence of bridging bone at the fusion site without observed motion on flexion-extension radiographs. Findings such as osteolysis around the implant or pedicle screws, extensive endplate cystic changes, or linear defects parallel to the endplates through intradiscal new bone formation were interpreted as signs of pseudarthrosis. Interobserver and intraobserver error and $\kappa$ assessments were analyzed to assure agreement in the CT outcomes assessment where interpretation of $\kappa$ were as follows: $<0.00=$ poor agreement, $0.00-0.20=$ slight agreement, $0.21-0.40=$ fair agreement, $0.41-0.60=$ moderate agreement, $0.61-0.80=$ substantial agreement, and $0.81-1.00=$ almost perfect agreement. Differences were resolved by consensus amongst the observers.

Results: In total, $96 \%$ of the 75 patients with a total of 85 levels $(96.5 \%$ of levels treated) achieved a fusion at 12 months. There were no perioperative or latent complications and no transfusions in all 75 patients.

Conclusions: In this population, $96 \%$ of the patients treated achieved the surgical objective in $96.5 \%$ of the levels treated.

Level of Evidence: IV

Clinical Relevance: The high rate of fusion, the lack of secondary morbidity with autologous bone harvest, and the clinical success account for the benefits of viable allograft matrix for MIS-TLIF use.

Lumbar Spine 
Keywords: minimally invasive translaminar interbody fusion (MITLIF), spinal fusion, viable allograft, case series, CT evaluation

\section{INTRODUCTION}

When nonoperative treatments fail to eliminate abnormal motion and instability, reduce pain, or enhance functional recovery, spinal fusion may provide symptomatic relief in select patients with spinal instability, stenosis, spondylolisthesis, and symptomatic degenerative disc disease. The implicit objective of a lumbar fusion is to establish an environment that will facilitate controlled bone formation that bridges 2 adjacent spinal segments. The trend and rates of fusion over the past few years have been dramatic in the United States (US), resulting in a greater acceptance and higher incidence of surgical intervention. With this trend, the shift from traditional open surgery to minimally invasive techniques was embraced in an effort to reduce scar tissue formation, minimize soft tissue injury, and to incorporate graft extenders or biologic augments with the goal of improving patient outcomes. Modern minimally invasive spine surgery was introduced to surgical practice nearly 25 years ago with the description of tubular retractors to access and visualize anatomic structures in the lumbar spine. This technology has been extended to microendoscopic discectomy. ${ }^{1,2}$ With time, advances in technology, materials, implants, and surgical instrumentation have supported minimally invasive surgical (MIS) development as perhaps the most rapidly growing field of spine surgery. Today, MIS techniques and approaches have been adapted to treat a variety of spinal disorders that include degenerative disc disease, disc herniation, instability, deformity, fracture, infection, and some tumors. ${ }^{3}$ Other reasons supporting the widespread transition to minimally invasive spine techniques include decreased postoperative pain, decreased intraoperative blood loss, shorter postoperative hospital stay, faster return to normal activity, and reduced reoperation rates. These nonbiologic factors are inexorable components of delivery and cost of care. Data-driven outcomes that measure treatment efficacy, durability, and patient satisfaction depend on careful patient selection and explicit mutual understanding of expectations. In that constellation of patient satisfaction, symptom remission, and cost containment, adopting select areas of refinement emerge that can be driven by surgical technology, physician competence, facility efficiency, and judicious biologic accentuation.

In that orchestra of thought, perhaps the most resonant asset to normalizing variation was the introduction of recombinant bone morphogeneic factor as an osteogenic enhancement to spinal fusion, emerging from the introduction of bone morphogenetic proteins (BMPs) by Marshall Urist in 1965 in which the osteoinductive properties of demineralized bone matrix (DBM) were recognized. ${ }^{4}$ Extensive studies have been published that speak to DBM as both a substitute and extender of autograft bone. ${ }^{5}$ With a better understanding and confidence that fusion agents could be used to induce bone formation, surgical use increased and culminated when the US Food and Drug Administration (FDA) granted premarket approval for the use of InFUSE (rhBMP-2, Medtronic-Sofamor Danek, Memphis, Tennessee) for single-level anterior lumbar interbody fusion procedures from L4 to S1 when used in conjunction with the LT-CAGE Lumbar Tapered Fusion Device (Medtronic-Sofamor Danek) in 2002. ${ }^{6}$ The FDA subsequently approved osteogenic protein-1 (OP-1; rhBMP-7, Stryker, Kalamazoo, Michigan) for revision posterolateral lumbar spine fusion under a humanitarian device exemption (HDE), where harvesting of autograft was not possible or not expected to achieve solid arthrodesis. ${ }^{7}$

The use of these agents extended well beyond the FDA-approved applications, and nearly $85 \%$ of primary spine procedures utilizing BMP were considered off label. ${ }^{8}$ Despite the fact that the offlabel use of BMP for spine fusion has met with radiographic and clinical success, concerns were raised due to reports of rare but significant neurological or structural complications following the use of BMPs, particularly with interbody fusions. ${ }^{9-12}$ These reports compelled the spine community to address these issues from editorial positions within leading peer-reviewed journals. ${ }^{13}$ The controversy extended into a public debate and subsequently to a third party review of data that had been used to bring the product to market and sustain its evolution as the biologic enhancement of choice for surgical applications. ${ }^{14}$ Known as the Yale University Open Data Access (YODA) study, the investigation concluded and asserted that 
aggregate data analysis did not suggest that rhBMP2 was superior to autograft iliac bone graft. The study went further to offer surgeon guidance to the use of rhBMP-2 in the cervical spine, an awareness of complications of ectopic bone growth in posterolateral fusion, and caution when using BMP in transforaminal lumbar interbody fusion (TLIF) due to seroma formation. ${ }^{14}$ In the context of the warnings, the authors also weighed in that BMP-2 remains a viable option for complex cases when autograft iliac bone graft is not desirable or available.

Sourcing an alternative to InFUSE that is as clinically effective without the adverse events is an important consideration as current reports express concerns that, in addition to seroma formation referenced in the YODA study, radiculitis in concert with early inflammation following BMP-2 administration occurs in $11.3 \%$ in patients undergoing TLIF procedures with BMP-2. ${ }^{11,15}$ Other reports address the most common complications associated with posterior lumbar interbody fusion (PLIF) and TLIF which include subsidence, osteolysis, postoperative radiculopathy, heterotopic ossification, dural tear, interbody implant migration, or intraoperative neurologic injury. ${ }^{17}$ The overall complication rate varies from 8 to $80 \%$ with an average of $36.4 \% .{ }^{16}$ In concert with the focus and transition to MIS-TLIF procedures in clinical practice, a biologic alternative that supports functional efficiency in bone formation while diminishing adverse events would be welcomed.

One adaptation of the viable allograft concept has been commercialized in an allograft bone carrier that retains a biocompatible, mesenchymal stem cell-rich population that also includes a physiologically enriched primitive marrow cell line. ${ }^{17-20}$ Separate from composition, a critical hallmark of this product (VIA Graft, Vivex Biomedical, Marietta, Georgia) is afforded in the cell protection by a cryopreservative. Unlike dimethlyl sulfoxide (DMSO), which has been shown to be toxic to cells at concentrations currently used to protect living cells during freezing, this polyampholyte-based material protects the cells while frozen, preserves the phenotypic expression, and is not toxic to either the cells being implanted or the host tissue into which it is placed..$^{21,22}$

Surgeons have avidly tracked and adopted the development of biologic enhancement technologies over the past 50 years and continue today to seek more efficient methods that will assure therapeutic relief for patients. While it is important to circumvent risks assigned by the YODA study, the essence of intervention after safety is to establish efficacy of care. Following 12 months of active clinical use of VIA Graft with no reported complications attributed to the graft itself, this retrospective review was initiated to evaluate outcomes of a single-practice, single-surgeon intervention in 75 consecutive patients undergoing MIS-TLIF surgery.

\section{METHODS}

A retrospective chart review identified all patients treated for degenerative conditions of the spine by a MIS-TLIF procedure and received VIA Graft cellular bone matrix with a minimum of 12-month follow up. Data acquired included age, gender, diagnosis, levels fused, complications, date of surgery, and date of last follow up. All patients in this review were treated by a MIS-TLIF procedure to achieve restoration of normal spinal alignment to improve the biomechanics of the spine, stabilization of the spinal segment to promote osseous fusion, and through minimal disruption of blood supply and tissue damage promote fusion and optimize function.

\section{Surgical Procedure}

All patients underwent a minimally invasive tube TLIF using an expandable interbody device Globus Rise or Caliber (Globus Medical, Audubon, Pennsylvania), and bilateral percutaneous pedicle screw construct with posterolateral grafting. Depending on medical comorbidities, the procedures were either performed in the main hospital operating room or the outpatient center. After induction of general anesthesia using total intravenous anesthesia (TIVA), placement of neuromonitoring leads, and positioning on a Jackson sling-top table, orthogonal anterior-posterior and lateral c-arms were positioned. Starting points were localized using image guidance. The approach side was determined based on patient symptoms, and on that side, a 2.5$\mathrm{cm}$ Wiltse incision was performed. This incision was used for the TLIF and ipsilateral screw placement. On the contralateral side, two 1-cm incisions were made corresponding to the pedicles. Jamshidi transpedicle cannulation was performed at all 4 pedicles. Then $15-20 \mathrm{~cm}^{3}$ of bone marrow was aspirated from each pedicle. Guidewires were then 

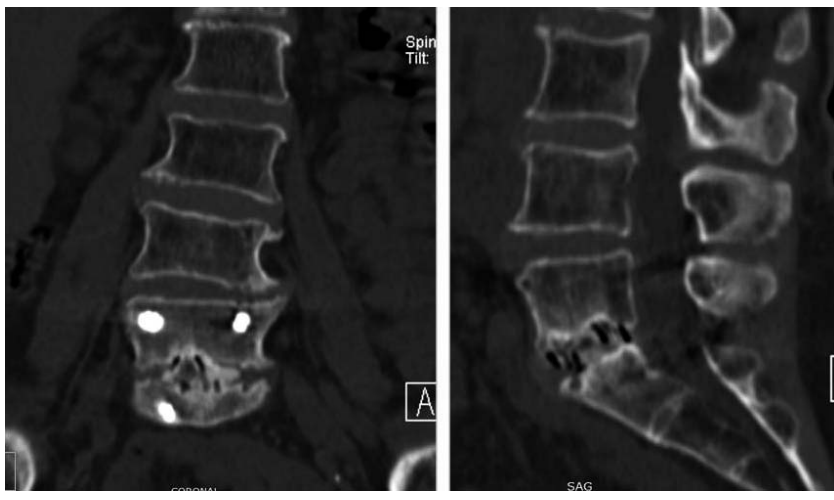

Figure 1. A 54-year-old woman underwent treatment for radiculopathy secondary to disc herniation. Bridging bone is apparent at the L5-S1 intervertebral level.

inserted, and each pedicle was tapped. The guidewires were then folded out of the way, and serial dilation was performed through the Wiltse incision on the approach side. A 22-mm tube retractor system was docked over the facet complex, and a complete facetectomy and laminectomy was performed. Kambin's triangle was entered, neural elements protected, and a complete discectomy was performed. Serial interbody trialing was accomplished with an expandable trial; the implant range was selected, and the endplates underwent final preparation. An endplate perforator was deployed to create bleeding bone and the disc space was grafted until full with VIA Graft. The expandable cage was prefilled with a compressed cancellous sponge and then inserted obliquely across midline and expanded until torque limited. Contralateral decompression was then performed if distraction did not provide enough indirect decompression. Wounds were closed in a routine layered fashion over vancomycin powder.

\section{Biologics}

Three separate areas of the anatomy received different biological components to support fusion enhancement. Following a standard approach and disc preparation for an interbody arthrodesis, VIA Graft cellular allograft was implanted within the disc and was then prepared to receive the implant. Each of the implants was filled with a cancellous sponge (VegaGraft, Vivex Biomedical) soaked in bone marrow concentrate. Posteriorly, vertebral bodies were stabilized with pedicle screws, and the vertebrae to be fused were packed with a slurry of beta-tricalcium phosphate as a bulking agent
(Callisto, Vivex Biomedical) and bone marrow concentrate.

\section{Postoperative Surveillance}

Postoperative computed tomographies (CTs) were obtained for all patients at 3 and 12 months. All CTs were done on a Siemens Sensation 16-slice scanner (Siemens Medical Solutions, Melvern, Pennsylvania). Scans were obtained through the lower thoracic and lumbosacral spine in 2-mm intervals and formatted for bone and soft tissue in axial, sagittal, and coronal planes. In addition, digital anteroposterior and lateral flexion and extension radiographs were obtained at 2, 6, 12, 26, and 52 weeks postsurgery.

Adverse events including infection, seroma and hematoma formation, neurologic injury, dural tear, revision, and evidence of immune response were evaluated (unexplained fever, local erythema) and patient comorbidities (tobacco abuse and diabetes) defined for the entire population of patients.

\section{Radiologic Review}

Independent blinded review of fusion was obtained by a board certified musculoskeletal radiologist and an experienced board certified orthopaedic surgeon to assess patient fusion status. Spinal segments were deemed fused if 12-month CT scans demonstrated evidence of bridging bone at the intervertebral fusion site without observed motion on flexion-extension radiographs (Figure 1). In this evaluation, the central fusion area to be considered was the intervertebral disc space, and determinations were not attended to the posterolateral anatomy. Findings such as osteolysis around the implant or pedicle screws, extensive endplate cystic changes, or linear defects parallel to the endplates through intradiscal new bone formation were interpreted as signs of pseudarthrosis. ${ }^{23}$ Interobserver and intraobserver error and $\kappa$ assessments were analyzed to assure agreement in the CT outcomes assessment where interpretation of $\kappa$ was as follows: $<0.00=$ poor agreement, $0.00-0.20=$ slight agreement, $0.21-0.40=$ fair agreement, $0.41-$ $0.60=$ moderate agreement, $0.61-0.80=$ substantial agreement, and $0.81-1.00=$ almost perfect agreement. Differences were resolved by consensus amongst the observers. 
Table 1. Patient demographics.

\begin{tabular}{lc}
\hline Diagnosis & No. (\%) \\
\hline Retrolisthesis & $10(13 \%)$ \\
Facet cyst & $8(8 \%)$ \\
Adjacent segment & $5(7 \%)$ \\
Stenosis & $53(71 \%)$ \\
Spondylolysis & $19(25 \%)$ \\
Spondylolisthesis & $46(61 \%)$ \\
Disk herniation & $11(15 \%)$ \\
Scoliosis & $6(8 \%)$ \\
\hline
\end{tabular}

\section{RESULTS}

There were 75 consecutive adult patients with degenerative conditions of the lumbar spine who underwent MIS-TLIF surgery of which $40(53 \%)$ were male and $35(47 \%)$ were female. Mean age, height, and weight were 58 years, $170.18 \mathrm{~cm}$ (67 in), and $88.45 \mathrm{~kg}$ (195 lbs), respectively. The mean body mass index was 30 . There were 16 patients $(21 \%)$ who smoked and $12(16 \%)$ with a history of diabetes. Diagnoses are shown in Table 1. In total, $96 \%$ of the 75 patients with a total of 85 levels (96.5\% of levels treated) achieved a fusion at 12 months. There were no perioperative or latent complications and no transfusions in all 75 patients. Eleven patients in this series had undergone a prior decompressive procedure and had retained motion (no spontaneous fusion) while developing recurrent pathology. All previously operated patients subsequently underwent an MIS-TLIF, and fusion was achieved in each patient. One patient who had an L5-S1 PLIF and an attempted posterolateral fusion of L4-L5 developed a pseudarthrosis at L4-L5, but fused at L5-S1 following the MIS-TLIF procedure.

There were 3 pseudarthrosis in 3 of the 75 patients $(4 \%)$ and 3 of 85 levels $(3.5 \%)$ in all of these patients; 1 had never used tobacco, 1 had abstained for more than 17 years, and a third used approximately 0.75 pack of cigarettes daily. All 3 patients with pseudarthrosis underwent a subsequent anterior lumbar fusion with a new cage and VIA Graft. These patients are undergoing clinical and radiographic surveillance to assess for fusion and similarly have obtained successful fusion on further clinical review. Ten patients underwent a 2level fusion, and 65 had a 1-level fusion (Figure 2). There were no pseudarthroses in patients with multilevel (2) fusions and 3 in patients with a 1level fusion, 2 at L5-S1 and 1 at L4-L5. There was substantial agreement (interobserver variability) among observers (absolute agreement $=96 \%$, Cohen's $\kappa=0.65)$.
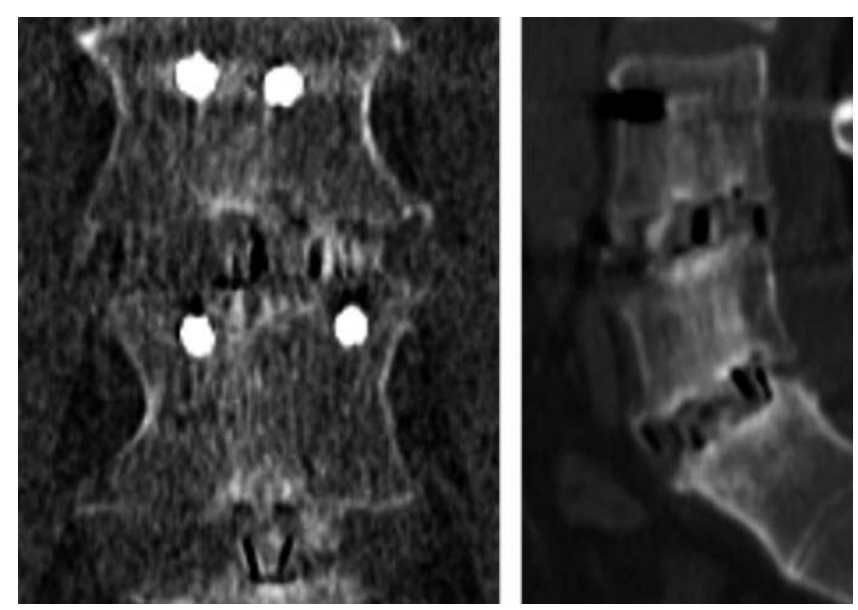

Figure 2. This 2-level fusion in a 45-year-old male treated for foraminal stenosis and radiculopathy who had undergone prior surgery. Mature fusion bridges L4-L5 and L5-S1.

\section{DISCUSSION}

There are many potential advantages in adopting the MIS-TLIF procedure. Reducing the need for retraction of the nerve root and thecal sac, avoiding the need and risk to enter the abdominal cavity, preserving the anterior and posterior longitudinal ligaments, not devitalizing adjacent soft tissues, allowing the disc space to be accessed unilaterally, and preserving the contralateral facet complex are strategies that might enhance outcome. In addition, decreased blood loss, decreased postoperative pain, decreased hospital stay, lower infections rates, ${ }^{24-31}$ and possibly decreased degeneration of the adjacent spinal levels would be expected to offer further refinement of therapeutic intent. ${ }^{32}$

The stated goal of the MIS-TLIF approach is fusion of the painful segments; this has been reported to be equivalent to corresponding open procedures ${ }^{26,33-38}$ with fusion rates consistently over $90 \%$ when using rh-BMP-2 (InFUSE). Less clear is the ideal source of biologic material to enhance the fusion process and provide sufficient stimulus for tissue regeneration and functional restoration. Even bone marrow aspiration is associated with morbidity, albeit far less than iliac crest grafting. Reported complications include anemia $(3.7 \%)$, early pain $(1.4 \%)$, persistent pain $(0.04 \%)$, and neuralgia $(0.06 \%)$. In the same series of patients, minor complications were observed in $2.3 \%$ of patients and major complications in $0.06 \%{ }^{38}$ In this series, minor complications were observed in $2.3 \%$.

Iliac crest bone grafting has been associated with major complications to include fracture and infection. ${ }^{39-41}$ Gruskay et al. ${ }^{42}$ observed longer hospital 
stays and operative times as well as increased blood transfusions in patients who underwent iliac crest bone grafting. One large study, 6499 patients, reported iliac crest bone grafting complications to be as high as $19.3 \% .^{43}$

Although spine fusion is enhanced by rhBMP-2, untoward side effects have been reported. Rihn et al. $^{44}$ cited complications in $33.6 \%$ of patients comparing 2 types of biologic augments, iliac crest bone graft and rhBMP-2. In this study, nonunion rates were exceptionally low, $3 \%$ in the autograft group and $3.5 \%$ in the rhBMP-2 group. The most common complications in the iliac crest group were persistent donor-site pain $(30.3 \%)$ and donor-site infection $(3.1 \%)$. In the rhBMP group, postoperative radiculitis $(14 \%)$ and vertebral osteolysis $(5.8 \%)$ were most common. ${ }^{44}$ Stensby et al. ${ }^{45}$ compared TLIF with and without rhBMP-2 and reported a statistically significant higher frequency of endplate resorption, new bone formation, and bone bridging present in TLIF augmented by rhBMP-2 compared with TLIF performed without rhBMP-2. Endplate resorption resolves without treatment in most cases after rhBMP-2 use. $^{45}$ In a comprehensive review of the potential early and latent side effects of rhBMP-2, estimates of adverse events associated with rhBMP-2 use in spine fusion ranged from 10 to $50 \%$, depending on the approach used. Although cervical fusion utilizing rhBMP-2 has been associated with high rates of complications, some life threatening, posterior lumbar interbody fusions have also demonstrated a number of complications to include radiculitis, ectopic bone formation, osteolysis, and poorer overall outcomes. In posterolateral fusions, rhBMP-2 use has been associated with adverse events that are equivalent to or greater than that of iliac crest bone graft harvesting. As many as 15 to $20 \%$ of subjects reported early back pain and leg pain, and higher doses of rhBMP-2 were also associated with a greater apparent risk of new malignancy. ${ }^{46}$

The high rate of fusion and the lack of secondary morbidity with allogeneic bone grafting and the clinical success in account with multiple levels strongly suggest the benefits of viable allograft matrix for MIS-TLIF use. Furthermore, there appear to be no measureable side effects related to the cell-matrix composite, no increased risk of infection or immune response. The bone substrate is composed of allogeneic cortical bone particles that are $100-300 \mu \mathrm{m} .{ }^{47-49}$ This morphology com- pared to larger and smaller particle sizes showed significantly improved consolidation in 6 weeks. When placed inside or juxtaposed to bone, these particles induce autologous stem cell migration, and the juxtaposition of the particles themselves are optimal conduits for stem cell movement within the matrix.

Matrix preparation is also important insofar as it is aseptically processed, thus preserving the natural constituent molecules that participate in bone healing and regeneration. In 1 large clinical study, micronized bone $(100-300 \mu \mathrm{m})$, used as a replacement for iliac crest autograft, could be correlated with early and robust bone formation. This matrix did not form heterotopic bone when placed in soft tissues. The residual bone particles resorb rapidly in the soft tissue. ${ }^{48}$

The cell component is comprised principally of stem cells phenotypically defined by accepted markers such as CD73, and CD 90 and SSEA-4 with a supraphysiologic concentration of marrow isolated adult multilineage inducible (MIAMI) cells (10-20\%). As the name implies, this cell type resides in the hypoxic marrow space, is highly inducible, and retains the ability to cross germ lines in tissue repair and regeneration. The combination of a robust matrix and osteogenic precursor and highly inducible cells placed in an area of local injury promotes physiologic bone healing that progresses in an ordered and controlled fashion. ${ }^{49}$ Assessed radiographically in this series of 75 patients, bone was not observed in the soft tissues, nor was it seen encroaching on the neuroforaminal structures.

Limitations to the findings in this study exist because, even though the data and images were collected prospectively, they were evaluated retrospectively. Additionally, all surgeries were performed by a single surgeon at a single site. Although all patients were treated by MIS-TLIF in a consecutive fashion, the study was not randomized or compared with patients undergoing open TLIF.

This study reported a technique using a central cancellous sponge - essentially a demineralized cancellous allograft that was soaked in autologous bone marrow that was obtained from the vertebral bone at the time of surgery. In the context of surgical care, adjunct use of allograft inside the implant, and allograft, albeit viable allograft, are not different approaches. The argument could be made that the use of a bulking beta-tricalcium phosphate in the 
posterolateral area might have biased the fusion, which does not meet the standards of the evaluation. In this study, fusion was determined by trabecular spicules crossing the intervertebral space. That observation was coupled to the lack of mobility in flexion-extension radiographs.

Clinical data (also collected, but not yet evaluated) would lend insight to the radiographic assessment and better attend the considerations of early relief, more efficient gains in quality of life, and in cost analysis regarding patient morbidity, return to work, facility cost, and the overall economics of minimally invasive procedures with advanced biologics in patient care. One criticism of the data might be directed at the lack of patient reported outcomes. While that is slated for a following report, each of the patients returned for 12-month radiographs and CT. Only 3 demonstrated nonfusion. All have been accepting of the improvement, and while the metric of recovery might be calibrated in pain, none of the patients in this study have returned for additional spinal surgery. Patients were not randomized in this study to receive an either/or implant of the viable allograft product. Based on clinical improvements to the surgical outcomes, the surgical procedure described here was deemed safe, effective, and therapeutically successful. In patients requiring vertebral body fusion, the technique described and qualified by consensus radiographic review was effective in this cohort of 75 patients.

Significance: High prevalence of back pain and spine complications exert an untold effect on the economy. Interventions that offer more efficient use of resources, including hospitalization, surgical use, surgeon use, and rehabilitation costs attendant to patient recovery are critically valued. Evidence of successful fusion has been demonstrated by living cell/matrix combinations that rivals that of growth factor administration. Reduction in grafting and morbidity benefits patients and facilities as well in a time of resource scrutiny.

\section{REFERENCES}

1. Faubert C, Caspar W. Lumbar percutaneous discectomy. Initial experience in 28 cases. Neuroradiology 1991;33(5):407-410.

2. Foley KT, Smith MM. Microendoscopic discectomy. Tech Neurosurg 1997;3:301-307.

3. American Academy of Neurological Surgeons. Minimally invasive spine surgery. http://www.aans.org/ Patients/Neurosurgical-Conditions-and-Treatments/Mini mally-Invasive-Spine-Surgery. Accessed March 20, 2018.
4. Urist MR. Bone: formation by autoinduction. Science 1965;150(3698):893-899.

5. Cammisa FP Jr, Lowery G, Garfin SR, et al. Two-year fusion rate equivalency between Grafton DBM gel and autograft in posterolateral spine fusion: a prospective controlled trial employing a side-by-side comparison in the same patient. Spine (Phila Pa 1976). 2004;29(6):660-666.

6. US Food and Drug Administration. Premarket approval (P000058). InFUSE Bone Graft/LT-CAGE Lumbar Tapered Fusion Device. https://www.accessdata.fda.gov/scripts/ cdrh $/ \mathrm{cfdocs} / \mathrm{cfpma} /$ pma.cfm? ID = P000058. Accessed May 23, 2017.

7. US Food and Drug Administration. Listing of DCRH humanitarian device exemptions. http://www.fda.gov/Medical Devices/ProductsandMedicalProcedures/DeviceApprovalsand Clearances/HDEApprovals/ucm161827.htm. Accessed November 16, 2017.

8. Ong KL, Villarraga ML, Lau E, Carreon LY, Kurtz SM, Glassman SD. Off-label use of bone morphogenetic proteins in the United States using administrative data. Spine (Phila Pa 1976). 2010;35(19):1794-1800.

9. Lewandrowski KU, Nanson C, Calderon R. Vertebral osteolysis after posterior interbody lumbar fusion with recombinant human bone morphogenetic protein 2: a report of five cases. Spine J 2007;7(5):609-614.

10. Meisel HJ, Schnoring M, Holhaus C, et al. Posterior lumbar interbody fusion using rhBMP-2. Eur Spine $J$ 2008;17(12):1735-1744.

11. Rihn JA, Patel R, Makda J, et al. Complications associated with single-level transforaminal lumbar interbody fusion. Spine J. 2009;9(8):623-629.

12. Carragee EJ, Mitsunaga KA, Hurwitz EL, Scuderi GJ. Retrograde ejaculation after anterior lumbar interbody fusion using rhBMP-2: a cohort controlled study. Spine J. 2011;11(6):511-516.

13. Carragee EJ, Ghanayem AJ, Weiner BK, Rothman DJ, Bono CM. A challenge to integrity in spine publications: years of living dangerously with the promotion of bone growth factors. Spine J. 2011;11(6):463-468.

14. Hustedt JW, Blizzard DJ. The controversy surrounding bone morphogenetic proteins in the spine: a review of current research. Yale J Biol Med. 2014;87(4):549-561.

15. Villavicencio AT, Burneikiene S. RhBMP-2-induced radiculitis in patients undergoing transforaminal lumbar interbody fusion: relationship to dose. Spine $J$. 2016;16(10):1208-1213.

16. Chrastil J, Patel AA. Complications associated with posterior and transforaminal lumbar interbody fusion. $\mathrm{J} \mathrm{Am}$ Acad Orthop Surg. 2012;20(5):283-291.

17. D'Ippolito G, Diabira S, Howard GA, Menei P, Roos BA, Schiller PC. Marrow-isolated adult multilineage inducible (MIAMI) cells, a unique population of postnatal young and old human cells with extensive expansion and differentiation potential. J Cell Sci. 2004;117(Pt 14):2971-2981.

18. Delcroix GJ, Garbayo E, Sindji L, et al. The therapeutic potential of human multipotent mesenchymal stromal cells combined with pharmacologically active microcarriers transplanted in hemi-parkinsonian rats. Biomaterials. 2011;32(6):1560-1573.

19. D'Ippolito G, Gomez LA, Curtis KM, et al. Isolation 
and characterization of swine MIAMI cells: a valuable animal model for adult stem cell therapy. CellR4. 2014;2(5):e1215.

20. Delcroix GJR, D'Ippolito G, et al. TGF- $\beta 3$-releasing pharmacologically active microcarriers combined with human cartilage microparticles drive MIAMI cells toward a hyaline cartilage phenotype. CellR4. 2015;3(1):e1394.

21. Men H, Agca Y, Critser ES, Critser JK. Beneficial effects of serum supplementation during in vitro production of porcine embryos on their ability to survive cryopreservation by open pulled straw vitrification. Theriogenology. 2005;64(6):1340-1349.

22. Son JH, Kim KH, Nam YK, Park JK, Kim SK. Optimization of cryoprotectants for cryopreservation of rat hepatocyte. Biotechnol Lett. 2004;26(10):829-833.

23. Williams AL, Gornet MF, Burkus KJ. CT evaluation of lumbar interbody fusion: current concepts. Am J Neuroradiol. 2005;26(8):2057-2066.

24. Djurasovic M, Rouben DP, Glassman SD, Casnellie MT, Carreon LY. Clinical outcomes of minimally invasive versus open TLIF: a propensity-matched cohort study. Am J Orthop (Belle Mead NJ). 2016;45(3):E77-82.

25. Jin-Tao Q, Yu T, Mei W, et al. Comparison of MIS vs. open PLIF/TLIF with regard to clinical improvement, fusion rate, and incidence of major complication: a meta-analysis. Eur Spine J. 2015;24(5):1058-1065.

26. Liu C, Zhou Y. Percutaneous endoscopic lumbar discectomy and minimally invasive transforaminal lumbar interbody fusion for recurrent lumbar disc herniation. World Neurosurg. 2017;98:14-20.

27. Lv Y, Chen J, Chen J, et al. Three-year postoperative outcomes between MIS and conventional TLIF in1-segment lumbar disc herniation. Minim Invasive Ther Allied Technol. 2017;26(3):168-176.

28. Vazan M, Gempt J, Meyer B, Buchmann N, Ryang YM. Minimally invasive transforaminal lumbar interbody fusion versus open transforaminal lumbar interbody fusion: a technical description and review of the literature. Acta Neurochir (Wien). 2017;159(6):1137-1146.

29. Wang YP, An JL, Sun YP, Ding WY, Shen Y, Zhang W. Comparison of outcomes between minimally invasive transforaminal lumbar interbody fusion and traditional posterior lumbar intervertebral fusion in obese patients with lumbar disk prolapse. Ther Clin Risk Manag. 2017;13:87-94. https:// doi.org/10.2147/TCRM.S117063.

30. Xie L, Wu WJ, Liang Y. Comparison between minimally invasive transforaminal lumbar interbody fusion and conventional open transforaminal lumbar interbody fusion: an updated meta-analysis. Chin Med J (Engl). 2016;129(16):196986. https://doi.org/10.4103/0366-6999.187847

31. Yang Y, Liu B, Rong LM, et al. Microendoscopyassisted minimally invasive transforaminal lumbar interbody fusion for lumbar degenerative disease: short-term and medium-term outcomes. Int J Clin Exp Med. 2015 Nov 15;8(11):21319-21326.

32. Li XC, Huang CM, Zhong CF, Liang RW, Luo SJ. Minimally invasive procedure reduces adjacent segment degeneration and disease: new benefit-based global meta-analysis. PLoS One. 2017;12(2):e0171546. https://doi.org/10.1371/jour nal.pone.0171546

33. Fan G, Wu X, Yu S, Sun Q, Guan X, Zhang H, et al. Clinical outcomes of posterior lumbar interbody fusion versus minimally invasive transforaminal lumbar interbody fusion in three-level degenerative lumbar spinal stenosis. Biomed Res Int. 2016;2016:4679865.

34. Goldstein CL, Macwan K, Sundararajan K, Rampersaud YR. Perioperative outcomes and adverse events of minimally invasive versus open posterior lumbar fusion: metaanalysis and systematic review. J Neurosurg Spine. 2016; 24(3):416-427. https://doi.org/10.3171/2015.2.SPINE14973

35. Khan NR, Clark AJ, Lee SL, Venable GT, Rossi NB, Foley KT. Surgical outcomes for minimally invasive vs open transforaminal lumbar interbody fusion: an updated systematic review and meta-analysis. Neurosurgery. 2015;77(6):847-874; discussion 874. https://doi.org/10.1227/NEU.0000000000000913

36. Lee HJ, Kim JS, Ryu KS. Minimally invasive TLIF using unilateral approach and single cage at single level in patients over 65. Biomed Res Int. 2016;2016:4679865.

37. Terman SW, Yee TJ, Lau D, Khan AA, La Marca F, Park P. Minimally invasive versus open transforaminal lumbar interbody fusion: comparison of clinical outcomes among obese patients. J Neurosurg Spine. 2014;20(6):644-652. https://doi. org/10.3171/2014.2.SPINE13794

38. Virdee JS, Nadig A, Anagnostopoulos G, George KJ. Comparison of peri-operative and 12-month lifestyle outcomes in minimally invasive transforaminal lumbar interbody fusion versus conventional lumbar fusion. $B r \quad J$ Neurosurg. 2017;31(2):167-171.

39. Ahlmann E, Patzakis M, Roidis N, Shepherd L, Holtom P. Comparison of anterior and posterior iliac crest bone grafts in terms of harvest-site morbidity and functional outcomes. J Bone Joint Surg Am. 2002;84-A(5):716-720.

40. Calori GM, Colombo M, Mazza EL, Mazzola S, Malagoli E, Mineo GV. Incidence of donor site morbidity following harvesting from iliac crest or RIA graft. Injury. 2014;45(Suppl 6):S116-S120. https://doi.org/10.1016/j.injury. 2014.10.034

41. Loeffler BJ, Kellam JF, Sims SH, Bosse MJ. Prospective observational study of donor-site morbidity following anterior iliac crest bone-grafting in orthopaedic trauma reconstruction patients. J Bone Joint Surg Am. 2012;94(18):1649-1654.

42. Gruskay JA, Basques BA, Bohl DD, Webb ML, Grauer JN. Short-term adverse events, length of stay, and readmission after iliac crest bone graft for spinal fusion. Spine (Phila Pa 1976). 2014;39(20):1718-1724. https://doi.org/10. 1097/BRS.0000000000000476

43. Dimitriou R, Mataliotakis GI, Angoules AG, Kanakaris NK, Giannoudis PV. Complications following autologous bone graft harvesting from the iliac crest and using the RIA: a systematic review. Injury. 2011;42(Suppl 2):S3-S15. https://doi. org/10.1016/j.injury.2011.06.015

44. Rihn JA, Makda J, Hong J, Patel R, Hilibrand AS, Anderson DG, et al. The use of rhBMP-2 in single-level transforaminal lumbar interbody fusion: a clinical and radiographic analysis. Eur Spine J. 2009;18(11):1629-1636. https:// doi.org/10.1007/s00586-009-1046-1051

45. Stensby JD, Kaliney RW, Alford B, Shen FH, Patrie JT, Fox MG. Radiographic appearance of transforaminal lumbar interbody fusion performed with and without recombinant human morphogenetic protein-2. AJR Am J Roentgenol. 2016;206(3):588-594. https://doi.org/10.2214/AJR.15.14503

46. Carragee EJ, Hurwitz EL, Weiner BK. A critical review 
of recombinant human bone morphogenetic protein-2 trials in spinal surgery: emerging safety concerns and lessons learned. Spine J. 2011;11(6):417-491. https://doi.org/10.1016/j.spinee. 2011.04.023

47. Malinin TI, Carpenter EM, Temple HT. Particulate bone graft in incorporation in regeneration of osseous defects: Importance of particle sizes. Open Orthop J. 2007;1:19-24.

48. Temple HT, Malinin TI. Microparticulate cortical allograft: an alternative to autograft in the treatment of osseous defects. Open Orthop J. 2008;2:91-96.

49. Temple HT, Ganey T, Delcroix G, Schiller P, D'Ippolito G, Malinin TI. Bone regeneration: microparticulate and biomimetic strategies. Current Tissue Engineering. 2016;5(1):4 10.

Disclosures and COI: None of the authors are employees of Vivex Biomedical, Inc. WCT receives no royalties, or has any other disclosures. HTT is a consultant for Vivex Biomedical, Inc. but received no compensation to write this manuscript and did no surgeries. TS has no disclosures. TG is a consultant for Vivex Biomedical, Inc. but received no compensation to write this manuscript and did no surgeries.

Corresponding Author: Timothy Ganey, Vivex Biomedical, 3200 Windy Hill Road, Suite 1650 West, Atlanta, GA 30339; Phone: (888) 6847783; Email: timganey@vivex.com.

Published 30 March 2018

This manuscript is generously published free of charge by ISASS, the International Society for the Advancement of Spine Surgery. Copyright (C) 2018 ISASS. To see more or order reprints or permissions, see http://ijssurgery.com. 